\title{
Transport of heavy metals into and out of the Seto Inland Sea, Japan
}

\author{
KiminORI ShitASHima* and Hiroyuki Tsubota \\ School of Biosphere Sciences, Hiroshima University, 1-1 Higashisenda Machi, \\ Naka-ku, Hiroshima 730 Japan
}

(Received February 8, 1990; Accepted September 4, 1990)

\begin{abstract}
Total and dissolved concentrations of heavy metals- $\mathrm{V}, \mathrm{Mn}, \mathrm{Fe}, \mathrm{Co}, \mathrm{Ni}, \mathrm{Cu}, \mathrm{Zn}, \mathrm{Mo}, \mathrm{Cd}$ and $\mathrm{Pb}-$ in the Seto Inland Sea and in surface water from the adjacent seas of Japan have been determined. The water samples were collected with a specially designed clean sampler, and particulates were separated by filtration and/or centrifugation in a clean bench on board ship or in a clean room on land. The heavy metals were preconcentrated with a chelating resin column and detected by GFAAS in a clean laboratory on land. All the elements analyzed were divided into three groups in accordance with the ratio of dissolved to total concentrations for the Seto Inland Sea. $\mathrm{Fe}, \mathrm{Mn}$ and $\mathrm{Pb}$ were mostly particulate forms, while $\mathrm{Cu}, \mathrm{Zn}$ and $\mathrm{Co}$ were divided fifty-fifty between dissolved and particulate forms. $\mathrm{Cd}, \mathrm{Ni}, \mathrm{Mo}$ and $\mathrm{V}$ were almost dissolved forms. Two different methods for separating particles were compared to determine the characteristics of particulates.

The flux of heavy metals from the Inland Sea to the open ocean was estimated, assuming that only the dissolved forms of the metals are transported outward.
\end{abstract}

\section{INTRODUCTION}

A large amount of both natural and anthropogenic heavy metals are supplied to estuaries from the land through rivers. An estuary is a junction point for the transport of heavy metals to the ocean. In an estuary, river water mixes with saline water, and physical and chemical conditions change drastically. Organic matter concentrations are very high and heavy metals behave according to their physiochemical characteristics and biological roles. Heavy metals are removed in particulate form from sea water by coagulation following the increases of salinity (Li et al., 1984; Ackroyd et al., 1986), and by coagulation and adsorption with particulate organic matter or various minerals (Boyle et al., 1977; Sholkovitz, 1978; Sholkovitz and Copland, 1981; Gibbs, 1986). Many factors affect the distribution and behavior of heavy metals in the estuary. To clarify each factor, various studies have been performed, i.e., surface microlayer sampling (Hardy et al., 1985), removal of particulates by the filtration method (Windom et al., 1983; Danielsson et al., 1983; Mart and Nurnberg, 1986), study of the particulate composition of heavy metals (Feely et al., 1986; Akagi et al., 1988) and estimate of dissolved chemical species (Batley and Garoner, 1978; Hart and Davies, 1981).

However, there is still no satisfactory explanation of factors and mechanisms which govern the distribution and behavior of heavy metals in estuaries. One reason is that the determination of individual chemical species is quite difficult. Moreover, before the last decade, the analytical results for the concentration of heavy metals in estuaries may be unreliable. The nature of the

*Present address: Central Research Institute of Electric Power Industry, 1646 Abiko, Abiko-city, Chiba 270-11 Japan 
estuarine zone is dependent on the topography, water quality of the river draining into, the distance from the river mouth to the shelf edge and so on. This is another factor which complicates the study of the estuary. The study on the behavior of heavy metals in the estuary, therefore, should be based on sampling from various types of estuaries, separation of dissolved and particulate forms for each metal, comparison of heavy metals having different characterstics and the introduction of clean techniques.

Most estuarine processes proceed rapidly along the Japan coast, because of its steep topography, short rivers and narrow estuaries. It is rather difficult to investigate the behavior and the fate of materials which are carried to estuaries through rivers, because they are rapidly transported to the ocean. The Seto Inland Sea was, therefore, selected as our experimental field. The Inland Sea is joined to the open ocean by four narrow channels, and consists of several basins and bays which are connected to each other through narrow straights. The area of the Inland Sea is $17.1 \times 10^{3} \mathrm{~km}^{2}$, the average depth being $31 \mathrm{~m}$. Among the bays, Osaka and Hiroshima bays are semi-closed and have rather large rivers draining. The inner parts of these two bays are considered to be good places to investigate rapid estuarine processes. In contrast, at the offshore, or central part, of the Inland Sea, salinity ranges from 31.5 to $34 \%$, and physical and chemical processes proceed slowly. The heavy metals carried by rivers encounter drastic removal processes followed by their transport offshore into the Inland Sea. There, the metals have rather slow reactions and are gradually transported to the open ocean. Most of the water in the Inland Sea is exchanged by the tidal current through two of the four channels. The residual current is quite small and directed eastward. The mean residence time of water in the Inland Sea was estimated as $1.2 \mathrm{y}$ (Takeoka, 1984; Fujiwara, 1985).

A preliminary study (Akagi et al., 1986) on the total heavy metal concentrations in and out of the Inland Sea is the only acceptable work on the heavy metals in the water of the Inland Sea, because a clean technique was applied to this study. They reported that the concentrations of heavy metals decreased with increasing salinity in the offshore area of the Inland Sea. They also pointed out that the chemical and physical features of suspended particles including biological substances should be examined to understand further the behavior and distribution of trace metals in the coastal areas.

Thus, the purpose of this study is to elucidate the distributions of dissolved and particulate forms of heavy metals in an estuary, and to reveal the processes of their removal and supply in the estuary and their transport to the ocean. In this study, ten heavy metals- $\mathrm{V}, \mathrm{Mn}, \mathrm{Fe}, \mathrm{Co}$, $\mathrm{Ni}, \mathrm{Cu}, \mathrm{Zn}, \mathrm{Mo}, \mathrm{Cd}$ and $\mathrm{Pb}$-having different characteristics are chosen as indicators. Clean techniques for all steps of the experiments-such as sampling, separation of particulates, and analytical treatment-are introduced in this study. Total and dissolved heavy metal concentrations in the Inland Sea are determined and the transport of heavy metals from the Inland Sea to the open ocean is discussed.

\section{Sampling and Analytical Procedures}

The sampling stations are shown in Fig. 1. Surface, subsurface and bottom seawater samples were collected in the area from Hiroshima Bay to Iyo Nada and from Osaka Bay to Kii Channel, and in the central area of the Seto Inland Sea from Aki Nada to Harima Nada. The R/V Toyoshio Maru of the Faculty of Applied Biological Science, Hiroshima University, was utilized for these sampling cruises. Surface seawater was sampled with a self-made sampler, consisting of a $6 \mathrm{~L}$ polyethylene bottle at the head of the ship running at 2 knots to avoid contamination from the ship. Subsurface and bottom seawater samples were collected by a specially designed contamination-free sampler (Tsubota, 1985).

To remove particles, the samples were immediately filtered through a nitric acid-cleaned 0.4 $\mu \mathrm{m}$ Nuclepore filter using a nitrogen-pressurized 


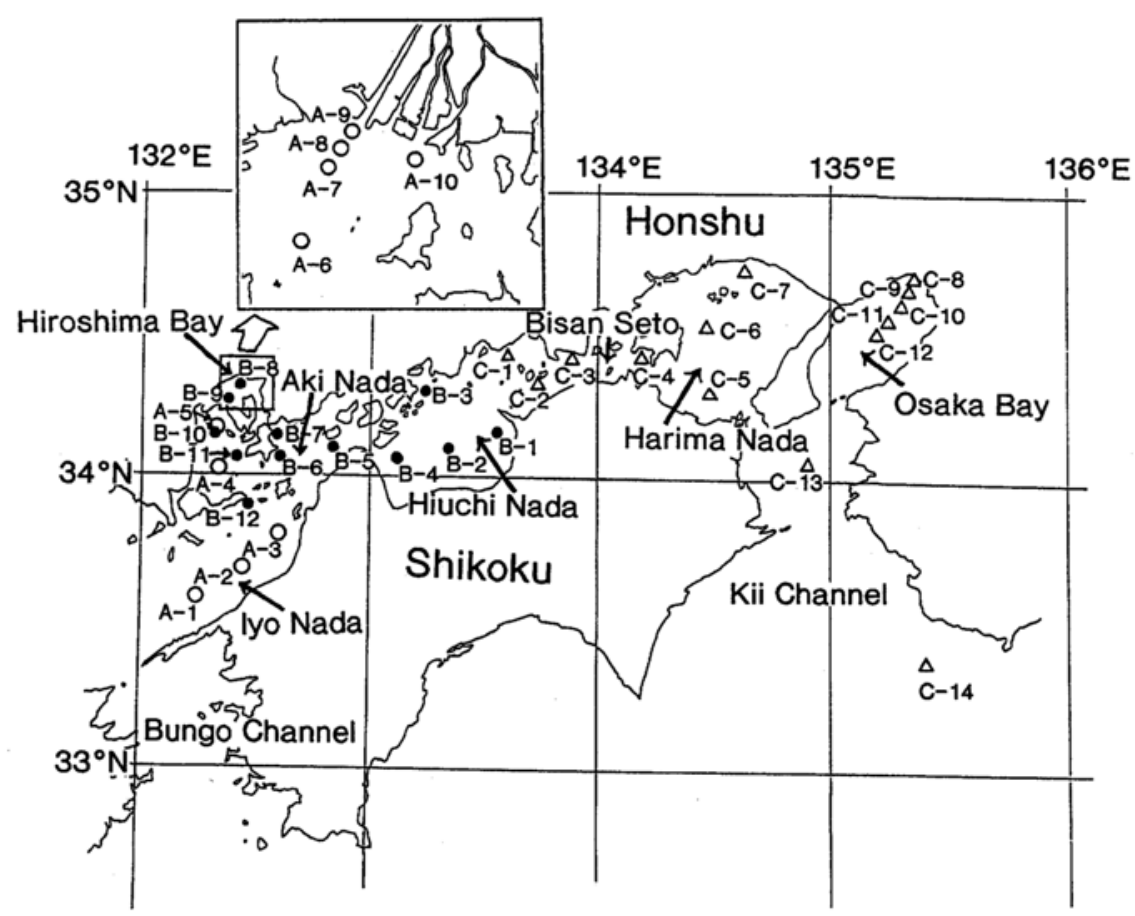

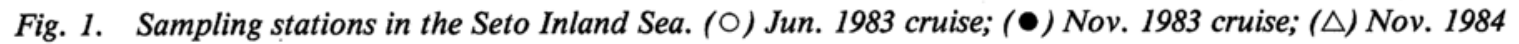
cruise.

Teflon in-line filtration apparatus in clean-bench on board, or centrifugalized for 1 hour at 6000 rpm $(5000 \mathrm{G})$ in Class-100 clean room in the laboratory on land within 6 hours after sampling. The samples for total and dissolved heavy metal determination were stored in a cleaned plyethylene bottle and acidified to $\mathrm{pH}$ lower than 2 with sub-boiled nitric acid. They were kept for about 2 months in oder to dissociate organically bound metals completely.

To the acidified $1 \mathrm{~L}$ sample, $1 \mathrm{~mL}$ acetic acid was added and a $\mathrm{pH}$ was adjusted to $5.3 \sim 5.5$ with aqueous ammonia. The solution was passed through a Chelex-100 column $(16 \phi \times 160 \mathrm{~mm})$. The column was washed with $200 \mathrm{~mL} 1 \mathrm{M}$ ammonium acetate solution (pH 5.5) to remove major elements, followed by $50 \mathrm{~mL}$ of sub-boiled water. The heavy metals adsorbed on the column were eluted with $2 \mathrm{M}$ nitric acid. The eluate was dried on a hot plate in a nitrogen-flow-clean-box and then the residue was dissolved and diluted with $2 \mathrm{M}$ nitric acid to $10 \mathrm{~mL}$. Thus, 100 -fold preconcentration was achieved. Ten heavy metals in this solution were determined by graphite furnace atomic absorption spectrophotometer (Perkin-Elmer Model 5000 with HGA-500 and AS-40). Analytical precisions in percent for $\mathrm{V}, \mathrm{Mn}, \mathrm{Fe}, \mathrm{Co}, \mathrm{Ni}, \mathrm{Cu}, \mathrm{Zn}, \mathrm{Mo}, \mathrm{Cd}$ and $\mathrm{Pb}$ were $3,2,4,2,2,2,5,6,2$ and $2 \%$, respectively. The preconcentration process was performed in the clean room and all reagents and water used in this process were purified by subboiling distillation.

\section{Results AND Discussion}

\section{Distribution and behavior of heavy metals}

The results of heavy metal analyses for three cruises are presented in Tables 1 to 3 . The centrifugal method was employed to determine the dissolved heavy metal concentrations for the June 1983 cruise, and the filtlation method was employed for the other two cruises. In the results of this study, total heavy metal concentrations offshore in the Seto Inland Sea agree with those reported by Akagi et al. (1986). 
Table 1. Heavy Metal Concentrations and salinity for Jun. 1983 cruise

\begin{tabular}{|c|c|c|c|c|c|c|c|c|c|c|c|c|}
\hline Stn. & $\begin{array}{c}\text { Depth } \\
\text { (m) }\end{array}$ & $\underset{(\mathrm{ng} / \mathrm{l})}{\mathrm{Cu}}$ & $\underset{(\mu \mathrm{g} / 1)}{\mathrm{Zn}}$ & $\underset{(\mu \mathrm{g} / 1)}{\mathrm{Fe}}$ & $\begin{array}{c}\mathrm{Pb} \\
(\mathrm{ng} / \mathrm{l})\end{array}$ & $\underset{(\mu \mathrm{g} / \mathrm{l})}{\mathrm{Mn}}$ & $\underset{(\mathrm{ng} / \mathrm{l})}{\mathrm{Ni}}$ & $\underset{(\mathrm{ng} / \mathrm{l})}{\mathrm{Cd}}$ & $\begin{array}{c}\text { Co } \\
\text { (ng/l) }\end{array}$ & $\begin{array}{c}\mathrm{Mo} \\
(\mu \mathrm{g} / 1)\end{array}$ & $\underset{(\mu \mathrm{g} / 1)}{\mathrm{V}}$ & $\begin{array}{c}\mathrm{S} \\
(\% 0)\end{array}$ \\
\hline \multirow[t]{3}{*}{ A-1 } & $0-\mathrm{T}$ & 320 & 0.340 & 0.844 & 17 & 1.31 & 330 & 24 & 12 & 10.9 & 1.34 & 33.46 \\
\hline & $20-\mathrm{T}$ & 165 & 0.201 & 0.338 & 61 & 0.637 & 374 & 28 & 8.0 & 11.7 & 1.17 & 33.40 \\
\hline & $20-\mathrm{C}$ & 129 & 0.115 & 0.0956 & 9.0 & 0.515 & 167 & 15 & 6.1 & 11.3 & 1.49 & \\
\hline \multirow[t]{3}{*}{ A-2 } & $0-\mathrm{T}$ & 262 & 0.229 & 4.35 & 77 & 1.17 & 348 & 25 & 15 & 10.4 & 1.46 & 33.31 \\
\hline & $20-\mathrm{T}$ & 257 & 0.257 & 8.76 & 68 & 1.48 & 415 & 29 & 16 & 10.9 & 1.41 & 33.28 \\
\hline & $20-C$ & 115 & 0.134 & 1.17 & 6.4 & 1.55 & 194 & 18 & 4.4 & 11.3 & 1.73 & \\
\hline \multirow[t]{4}{*}{ A-3 } & $0-\mathrm{T}$ & 533 & 0.463 & 41.0 & 100 & 3.30 & 375 & 27 & 38 & 10.7 & 1.67 & 33.10 \\
\hline & $0-C$ & 202 & 0.156 & 1.69 & 6.3 & 0.934 & 192 & 16 & 12 & 10.4 & 1.46 & \\
\hline & $20-\mathrm{T}$ & 434 & 1.04 & 83.3 & 170 & 7.10 & 476 & 29 & 86 & 11.7 & 1.64 & 33.32 \\
\hline & $20-\mathrm{C}$ & 182 & 0.313 & 6.75 & 11 & 0.952 & 231 & 21 & 13 & 11.7 & 1.64 & \\
\hline \multirow[t]{4}{*}{ A-4 } & $0-\mathrm{T}$ & 461 & 0.606 & 19.1 & 47 & 4.59 & 293 & 17 & 24 & 12.2 & 1.84 & 33.06 \\
\hline & $0-\mathrm{C}$ & 201 & 0.32 & 1.25 & 23 & 1.07 & 242 & 19 & 11 & 11.1 & 1.41 & \\
\hline & $20-\mathrm{T}$ & 438 & 2.11 & 66.4 & 130 & 12.7 & 425 & 17 & 59 & 13.1 & 1.96 & 33.11 \\
\hline & $20-\mathrm{C}$ & 220 & 0.934 & 4.53 & 14 & 1.14 & 331 & 22 & 11 & 10.7 & 1.47 & \\
\hline \multirow[t]{2}{*}{ A-5 } & $0-\mathrm{T}$ & 582 & 0.885 & 3.87 & 39 & 6.25 & 320 & 17 & 17 & 9.34 & 1.48 & 32.70 \\
\hline & $0-\mathrm{C}$ & 313 & 0.592 & 0.586 & 2.8 & 0.297 & 276 & 21 & 8.3 & 10.7 & 1.23 & \\
\hline \multirow[t]{4}{*}{ A-6 } & $0-\mathrm{T}$ & 626 & 4.20 & 45.9 & 230 & 25.4 & 558 & 23 & 60 & 10.3 & 1.83 & 31.58 \\
\hline & $0-\mathrm{C}$ & 556 & 1.36 & 1.56 & 15 & 1.61 & 418 & 20 & 19 & 9.97 & 1.24 & \\
\hline & $17-\mathrm{T}$ & 463 & 1.42 & 48.8 & 78 & 26.2 & 355 & 17 & 39 & 12.4 & 1.70 & 32.63 \\
\hline & 17-C & 220 & 0.721 & 7.04 & 14 & 1.49 & 312 & 23 & 10 & 11.5 & 1.68 & \\
\hline \multirow[t]{2}{*}{ A-7 } & $0-\mathrm{T}$ & 1190 & 5.01 & 28.8 & 94 & 22.5 & 497 & 57 & 46 & 12.1 & 1.75 & 30.79 \\
\hline & $0-C$ & 737 & 2.18 & 1.78 & 8.4 & 1.45 & 398 & 44 & 16 & 10.6 & 1.26 & \\
\hline \multirow[t]{4}{*}{ A-8 } & $0-\mathrm{T}$ & 961 & 5.52 & 57.9 & 180 & 35.1 & 686 & 35 & 75 & 12.7 & 1.84 & 31.34 \\
\hline & $0-\mathrm{C}$ & 620 & 3.23 & 2.07 & 20 & 9.55 & 604 & 36 & 44 & 9.98 & 1.21 & \\
\hline & $8-\mathrm{T}$ & 423 & 1.94 & 16.1 & 35 & 11.3 & 361 & 16 & 25 & 11.4 & 1.68 & 32.47 \\
\hline & $8-C$ & 430 & 1.41 & 4.95 & 10 & 1.02 & 349 & 25 & 11 & 10.8 & 1.30 & \\
\hline \multirow[t]{2}{*}{ A-9 } & $0-\mathrm{T}$ & 1880 & 7.39 & 61.5 & 230 & 64.8 & 824 & 44 & 70 & 12.4 & 1.80 & 29.31 \\
\hline & $0-\mathrm{C}$ & 834 & 5.56 & 4.18 & 43 & 9.47 & 736 & 41 & 50 & 8.98 & 1.19 & \\
\hline \multirow[t]{2}{*}{ A-10 } & $0-\mathrm{T}$ & 1700 & 7.01 & 95.4 & 540 & 124 & 566 & 37 & 180 & 8.55 & 1.87 & 29.40 \\
\hline & $0-\mathrm{C}$ & 933 & 4.34 & - & 78 & 4.03 & 461 & 38 & 92 & 7.20 & 1.01 & \\
\hline
\end{tabular}

T: Total Metal; C: Dissolved Metal (centrifugal method).

The chief water movement in the Seto Inland Sea is a tidal crrent, while river discharges are rather small there. The behavior of elements flowing into the bay from the rivers is dominated not only by the dispersion of fresh water but also by bio-uptake and flocculate precipitation during the alternate tidal motions, even though these elements are dissolved in the river water. Consequently, the distribution of the elementsespecially particulate-forming and bio-essential-is very complicated in each bay. Therefore, we will ignore the differences between each bay or basin and discuss only the region offshore in the Inland Sea joining the two bays, Osaka Bay and Hiroshima Bay, to make up for the deficiency of low salinity regions. Hayami and Unoki (1970) separated the whole Inland Sea into 36 boxes and calculated the yearly-average chlorinity in each box. They pointed out that chlorinity increases from Harima Nada to Bungo and Kii Channel. Salinities in this study were in the same range and distribution as their results. This means that our samples were representative of the offshore Inland Sea from the viewpoint of salinity.

For $\mathrm{Fe}, \mathrm{Mn}$ and $\mathrm{Pb}$, dissolved concentrations were very low, ranging from a low salinity region (inner parts of Hiroshima Bay and Osaka Bay) to a high salinity region (Iyo Nada and Kii Channel). These metals were mostly in particulate form in the Seto Inland Sea. Danielsson et al. (1983) reported that $\mathrm{Fe}$ and $\mathrm{Pb}$ were mainly associated with particulate in the Göta River Estuary. Correlations of total and dissolved $\mathrm{Fe}$ 
Table 2. Heavy Metal Concentrations and salinity for Nov. 1983 cruise

\begin{tabular}{|c|c|c|c|c|c|c|c|c|c|c|c|c|}
\hline Stn. & $\begin{array}{c}\text { Depth } \\
\text { (m) }\end{array}$ & $\underset{(\mathrm{ng} / \mathrm{l})}{\mathrm{Cu}}$ & $\underset{(\mu \mathrm{g} / 1)}{\mathrm{Zn}}$ & $\underset{(\mu \mathrm{g} / 1)}{\mathrm{Fe}}$ & $\underset{(\mathrm{ng} / \mathrm{l})}{\mathrm{Pb}}$ & $\underset{(\mu \mathrm{g} / 1)}{\mathrm{Mn}}$ & $\underset{(\mathrm{ng} / \mathrm{l})}{\mathrm{Ni}}$ & $\underset{\text { (ng/l) }}{\mathrm{Cd}}$ & $\begin{array}{c}\mathrm{Co} \\
(\mathrm{ng} / \mathrm{l})\end{array}$ & $\begin{array}{c}\mathrm{Mo} \\
(\mu \mathrm{g} / \mathrm{l})\end{array}$ & $\underset{(\mu \mathrm{g} / \mathrm{l})}{\mathrm{V}}$ & $\underset{(\% 0)}{S}$ \\
\hline \multirow[t]{4}{*}{ B-1 } & $0-\mathrm{T}$ & 613 & 0.633 & 6.96 & 46 & 43.1 & 544 & 22 & 49 & 11.1 & 2.11 & 32.333 \\
\hline & $0-\mathrm{F}$ & 372 & 0.932 & 0.641 & 69 & 53.7 & 499 & 20 & 43 & 10.8 & 1.98 & \\
\hline & $20-\mathrm{T}$ & 563 & 0.729 & 57.4 & 110 & 20.9 & 430 & 22 & 63 & 12.5 & 2.44 & 32.532 \\
\hline & $20-\mathrm{F}$ & 478 & 1.09 & 0.868 & 97 & 29.5 & 360 & 23 & 28 & 10.6 & 2.03 & \\
\hline \multirow[t]{4}{*}{ B-2 } & $0-\mathrm{T}$ & 589 & 2.40 & 16.5 & 120 & 29.0 & 588 & 26 & 49 & 12.5 & 2.18 & 32.633 \\
\hline & $0-F$ & 518 & 2.62 & 0.818 & - & 15.9 & 521 & 23 & 39 & 10.3 & 1.73 & \\
\hline & $18-\mathrm{T}$ & 629 & 0.852 & 53.5 & 150 & 26.4 & 492 & 23 & 60 & 13.0 & 2.29 & 32.622 \\
\hline & $18-\mathrm{F}$ & 377 & - & 0.519 & 110 & - & 414 & 26 & 30 & 11.0 & 1.95 & \\
\hline \multirow[t]{4}{*}{ B-3 } & $0-\mathrm{T}$ & 461 & 0.661 & 20.3 & 87 & 28.3 & 378 & 32 & 38 & 12.5 & 2.22 & 32.602 \\
\hline & $0-\mathrm{F}$ & 372 & - & 0.834 & - & 20.1 & 342 & 35 & 25 & 10.7 & 1.84 & \\
\hline & $20-\mathrm{T}$ & 618 & 1.19 & 75.3 & 160 & 32.0 & 438 & 33 & 82 & 13.4 & 2.39 & 32.595 \\
\hline & $20-\mathrm{F}$ & 329 & 1.55 & 4.07 & 110 & 19.7 & 321 & 29 & 29 & 11.4 & 2.12 & \\
\hline \multirow[t]{2}{*}{ B-4 } & $0-\mathrm{T}$ & 593 & 0.937 & 32.5 & 93 & 19.9 & 405 & 21 & 45 & 12.6 & 2.23 & 32.729 \\
\hline & $22-\mathrm{T}$ & 594 & 1.15 & 40.1 & 91 & 19.6 & 427 & 20 & 43 & 12.6 & 2.11 & 32.782 \\
\hline B-5 & $0-\mathrm{T}$ & 421 & 0.583 & 8.01 & 34 & 3.30 & 317 & 20 & 14 & 10.3 & 1.91 & 32.887 \\
\hline \multirow[t]{4}{*}{ B-6 } & $0-\mathrm{T}$ & 650 & 0.500 & 12.6 & - & 1.96 & - & 9.0 & - & - & - & 33.012 \\
\hline & $0-F$ & 370 & 0.360 & 6.30 & - & 0.620 & - & 7.0 & - & - & - & \\
\hline & $47-\mathrm{T}$ & 470 & 0.790 & 21.2 & - & 2.03 & - & 8.0 & - & - & - & 33.045 \\
\hline & $47-\mathrm{F}$ & 460 & 0.510 & - & - & 0.86 & - & 6.0 & - & - & - & \\
\hline B-7 & $0-T$ & 399 & 0.359 & 27.3 & 110 & 5.27 & 438 & 18 & 21 & 9.39 & 1.89 & 32.979 \\
\hline \multirow[t]{2}{*}{ B-8 } & $0-T$ & 350 & 1.44 & 31.7 & - & 11.1 & - & 11 & - & - & - & 31.809 \\
\hline & $8-T$ & 450 & 1.44 & 55.5 & - & 13.9 & - & 12 & - & - & - & 31.839 \\
\hline \multirow[t]{2}{*}{ B-9 } & $0-T$ & 320 & 1.01 & 7.00 & - & 6.0 & - & 14 & - & - & - & - \\
\hline & $15-\mathrm{T}$ & 290 & 0.730 & 40.4 & - & 11.9 & - & 11 & - & - & - & 32.353 \\
\hline \multirow[t]{2}{*}{ B-10 } & $0-\mathrm{T}$ & 220 & 1.78 & 16.4 & - & 5.12 & - & 7.0 & - & - & - & 32.723 \\
\hline & $32-\mathrm{T}$ & 620 & 2.34 & 24.5 & - & 5.28 & - & 9.0 & - & - & - & 32.731 \\
\hline \multirow[t]{2}{*}{ B-11 } & $0-T$ & 210 & 2.15 & 16.3 & - & 3.12 & - & 8.0 & - & - & - & 33.003 \\
\hline & $27-\mathrm{T}$ & 360 & 0.530 & 27.5 & - & 4.22 & - & 12 & - & - & - & 32.984 \\
\hline \multirow[t]{2}{*}{ B-12 } & $0-\mathrm{T}$ & 200 & 0.310 & 17.4 & - & 2.69 & - & 9.0 & - & - & - & 33.052 \\
\hline & 53-T & 220 & 1.73 & 23.1 & - & 3.12 & - & 10 & - & - & - & 33.084 \\
\hline
\end{tabular}

T: Total Metal; F: Dissolved Metal (filtration method).

concentrations to salinity are given in Fig. 2. Total Fe concentrations show negative but weak correlation versus salinity. Their concentrations are distinctly higher in bottom waters than in surface waters for both total and dissolved Fe even in the central part of the Inland Sea. At these stations, Fe may be supplied from sediment by resuspension and re-dissolution. Except for some points encircled, which are mostly in the inner part of Hiroshima Bay in June '83, dissolved Fe shows a good linearity with salinity. Similar characteristics were obtained for $\mathrm{Mn}$ and $\mathrm{Pb}$. It is suggested that these heavy metals were removed rapidly as particles in the Inland Sea.

Dissolved concentrations of $\mathrm{Cu}, \mathrm{Zn}$ and $\mathrm{Co}$ were about one half of the total concentrations in the Inland Sea. Correlations of total and dissolved $\mathrm{Cu}$ concentrations with respect to salinity are given in Fig. 3. Both total and dissolved $\mathrm{Cu}$ concentrations show a good linerity and behave conservatively, except for points in some basins such as $\mathrm{Fe}$ (Fig. 2). No difference between surface and bottom water was found for both total and dissolved $\mathrm{Cu}$. A similar behavior was found for $\mathrm{Zn}$. The distribution of Co was considered to be grouped with $\mathrm{Fe}$, but the observed distribution for Co shows a pattern similar to $\mathrm{Cu}$ and $\mathrm{Zn}$. This is probably caused by the solubility of the hydrated oxide and the low abundance of Co. This physio-chemical behavior for some heavy metals will be discussed elsewhere.

No distinct differences between total and dissolved concentrations were found for $\mathrm{Cd}, \mathrm{Ni}$, Mo and V. These metals were mostly in the 
Table 3. Heavy Metal Concentrations and salinity for Nov. 1984 cruise

\begin{tabular}{|c|c|c|c|c|c|c|c|c|c|c|c|c|}
\hline Stn. & $\begin{array}{c}\text { Depth } \\
\text { (m) }\end{array}$ & $\underset{(\mathrm{ng} / \mathrm{l})}{\mathrm{Cu}}$ & $\underset{(\mu \mathrm{g} / \mathrm{l})}{\mathrm{Zn}}$ & $\underset{(\mu \mathrm{g} / \mathrm{l})}{\mathrm{Fe}}$ & $\underset{(\mathrm{ng} / \mathrm{l})}{\mathrm{Pb}}$ & $\underset{(\mu \mathrm{g} / \mathrm{l})}{\mathrm{Mn}}$ & $\underset{(\mathrm{ng} / \mathrm{l})}{\mathrm{Ni}}$ & $\underset{(\mathrm{ng} / \mathrm{l})}{\mathrm{Cd}}$ & $\begin{array}{c}\text { Co } \\
\text { (ng/l) }\end{array}$ & $\begin{array}{l}\mathrm{Mo} \\
(\mu \mathrm{g} / \mathrm{l})\end{array}$ & $\underset{(\mu \mathrm{g} / \mathrm{l})}{\mathrm{V}}$ & $\underset{(\% 0)}{S}$ \\
\hline \multirow[t]{2}{*}{$C-1$} & $0-\mathrm{T}$ & 850 & 1.47 & 36.2 & 130 & 7.98 & 633 & 38 & 36 & 10.3 & 2.20 & 32.946 \\
\hline & $7-\mathrm{T}$ & 797 & 1.41 & 35.0 & 150 & 13.0 & 711 & 44 & 35 & 9.52 & 2.17 & 32.933 \\
\hline \multirow[t]{4}{*}{ C-2 } & $0-\mathrm{T}$ & 418 & 1.16 & 40.6 & 130 & 7.38 & 596 & 42 & 31 & 11.7 & 2.32 & 33.145 \\
\hline & $0-F$ & 396 & 0.507 & 0.544 & 42 & 8.00 & 423 & 32 & 18 & 11.7 & 1.73 & \\
\hline & $21-\mathrm{T}$ & 963 & 2.16 & 84.2 & 250 & 15.5 & 710 & 39 & 79 & 12.0 & 2.47 & 33.172 \\
\hline & 21-F & 518 & 0.391 & 0.425 & 24 & 3.48 & 407 & 27 & 17 & 11.5 & 1.84 & \\
\hline C-3 & $0-\mathrm{T}$ & 617 & 0.530 & 27.6 & 150 & 12.6 & 563 & 32 & 35 & 10.7 & 2.17 & 32.970 \\
\hline \multirow[t]{4}{*}{ C-4 } & $0-\mathrm{T}$ & 910 & 1.90 & 66.4 & 190 & 10.2 & 614 & 41 & 53 & 13.1 & 2.65 & 32.800 \\
\hline & $0-\mathrm{F}$ & 609 & 0.943 & 0.485 & 21 & 0.328 & 448 & 42 & 6.4 & 12.0 & 1.86 & \\
\hline & $16-\mathrm{T}$ & 660 & 0.926 & 76.6 & 170 & 21.3 & 622 & 29 & 76 & 11.0 & 2.51 & 32.790 \\
\hline & $16-\mathrm{F}$ & 517 & 1.13 & 0.321 & 20 & 0.611 & 448 & 43 & 6.7 & 10.3 & 1.67 & \\
\hline \multirow[t]{4}{*}{ C-5 } & $0-\mathrm{T}$ & 400 & 0.714 & 16.7 & 66 & 7.00 & 392 & 18 & 21 & 10.8 & 2.14 & 32.979 \\
\hline & $0-\mathrm{F}$ & 325 & 0.593 & 0.262 & 27 & 1.45 & 372 & 15 & 11 & 11.1 & 1.74 & \\
\hline & $25-\mathrm{T}$ & 401 & 0.307 & 18.5 & 73 & 6.14 & 390 & 15 & 24 & 12.3 & 2.19 & 33.065 \\
\hline & $25-\mathrm{F}$ & 297 & 0.295 & 0.168 & 33 & 1.10 & 373 & 20 & 8.9 & 11.0 & 1.80 & \\
\hline \multirow[t]{6}{*}{ C-6 } & $0-\mathrm{T}$ & 424 & 0.453 & 28.4 & 82 & 8.97 & 423 & 16 & 26 & 11.9 & 2.13 & 33.027 \\
\hline & $0-F$ & 320 & 1.62 & 1.18 & 39 & 0.491 & 384 & 12 & 11 & 9.69 & 1.81 & \\
\hline & $30-\mathrm{T}$ & 427 & 0.438 & 31.6 & 96 & 13.3 & 446 & 16 & 28 & 11.7 & 2.09 & 33.029 \\
\hline & $30-\mathrm{F}$ & 368 & 0.611 & 0.220 & 44 & 1.47 & 405 & 12 & 10 & 11.4 & 1.90 & \\
\hline & $40-T$ & 389 & 0.381 & 30.2 & 94 & 12.1 & 439 & 13 & 27 & 11.5 & 1.94 & 33.031 \\
\hline & $40-\mathrm{F}$ & 330 & 0.441 & 0.324 & 47 & 1.54 & 383 & 12 & 9.0 & 10.4 & 1.75 & \\
\hline C-7 & $0-T$ & 485 & 0.913 & 33.1 & 120 & 9.78 & 483 & 19 & 35 & 11.7 & 2.16 & 32.800 \\
\hline C-8 & $0-\mathrm{T}$ & 940 & 6.29 & 62.8 & 190 & 75.9 & 3750 & 19 & 18 & 9.22 & 1.98 & 30.440 \\
\hline \multirow[t]{4}{*}{ C-9 } & $0-\mathrm{T}$ & 707 & 4.32 & 32.3 & 140 & 12.1 & 2950 & 15 & 91 & 8.55 & 1.69 & 31.127 \\
\hline & $0-\mathrm{F}$ & 490 & 3.21 & 2.21 & 32 & - & 2520 & 13 & 72 & 7.73 & 1.36 & \\
\hline & $12-\mathrm{T}$ & 633 & 2.29 & 73.5 & 240 & 27.6 & 1160 & 13 & 92 & 12.4 & 2.27 & 32.610 \\
\hline & $12-\mathrm{F}$ & 363 & 1.23 & 0.716 & 31 & 7.39 & 1010 & 11 & 34 & 10.8 & 1.65 & \\
\hline \multirow[t]{4}{*}{$C-10$} & $0-\mathrm{T}$ & 426 & 1.67 & 0.351 & 61 & 15.5 & 1520 & 14 & 49 & 9.57 & 1.59 & 32.213 \\
\hline & $0-F$ & 375 & 1.61 & 1.07 & 35 & 22.4 & 1390 & 15 & 49 & 11.3 & 1.53 & \\
\hline & 16-T & 393 & 0.946 & 30.0 & 120 & 26.0 & 893 & 14 & 42 & 9.86 & 1.96 & 33.006 \\
\hline & $16-\mathrm{F}$ & 301 & 0.746 & 0.537 & 23 & 3.85 & 764 & 9.5 & 23 & 10.23 & 1.57 & \\
\hline C-11 & $0-T$ & 401 & 1.56 & 0.775 & 110 & 18.4 & 1130 & 15 & 37 & 8.68 & 1.65 & 32.648 \\
\hline \multirow[t]{4}{*}{$C-12$} & $0-\mathrm{T}$ & 360 & 0.553 & 21.2 & 74 & 6.84 & 509 & 13 & 22 & 9.80 & 1.91 & 33.223 \\
\hline & $0-\mathrm{F}$ & 253 & 0.492 & 0.336 & 15 & 0.506 & 517 & 12 & 10 & 9.31 & 1.61 & \\
\hline & $30-\mathrm{T}$ & 408 & 0.513 & 25.8 & 89 & 5.35 & 595 & 13 & 26 & 9.79 & 1.84 & 33.213 \\
\hline & $30-\mathrm{F}$ & 294 & 0.565 & 2.81 & 30 & 0.596 & 609 & 14 & 12 & 11.0 & 1.71 & \\
\hline $\mathrm{C}-13$ & $0-\mathrm{T}$ & 208 & 0.206 & 14.4 & 66 & 15.5 & 309 & 7.6 & 17 & 11.7 & 1.90 & 34.038 \\
\hline \multirow[t]{4}{*}{ C-14 } & $0-\mathrm{T}$ & 30.1 & 0.006 & 0.415 & 15 & 0.275 & 149 & 1.4 & 1.1 & 12.6 & 1.81 & 34.549 \\
\hline & $0-F$ & - & - & - & - & 0.080 & 141 & - & - & 13.3 & 1.54 & \\
\hline & $50-\mathrm{T}$ & 28.1 & 0.00 & 0.505 & 11 & 0.182 & 155 & 2.2 & 1.1 & 13.6 & 1.68 & 34.448 \\
\hline & $50-\mathrm{F}$ & - & - & 0.557 & - & 0.055 & 148 & - & - & 12.8 & 1.60 & \\
\hline
\end{tabular}

T: Total Metal; F: Dissolved Metal (filtration method).

dissolved form in the Inland Sea. Danielsson et al. (1983) also reported that $\mathrm{Ni}$ was mostly in the dissolved from in the Göta River Estuary. Figure 4 shows the correlation of total and dissolved $\mathrm{Cd}$ concentrations with respect to salinity. Total and dissolved $\mathrm{Cd}$ concentrations decrease with increasing salinity and show negative correlation, with some expections such as Fe. No difference between surface and bottom water was found both total and dissolved Cd. A similar behavior was obtained for $\mathrm{Ni}$ and V. Mo showed positive correlation with salinity. It is considered that $\mathrm{Cd}, \mathrm{Ni}, \mathrm{Mo}$ and $\mathrm{V}$ are conservative and exist in seawater as a chloro-complex, chloro- and sulfate-complexes, molybdate anion and vanadate anion, respectively.

Comparison between centrifugal and filtration 

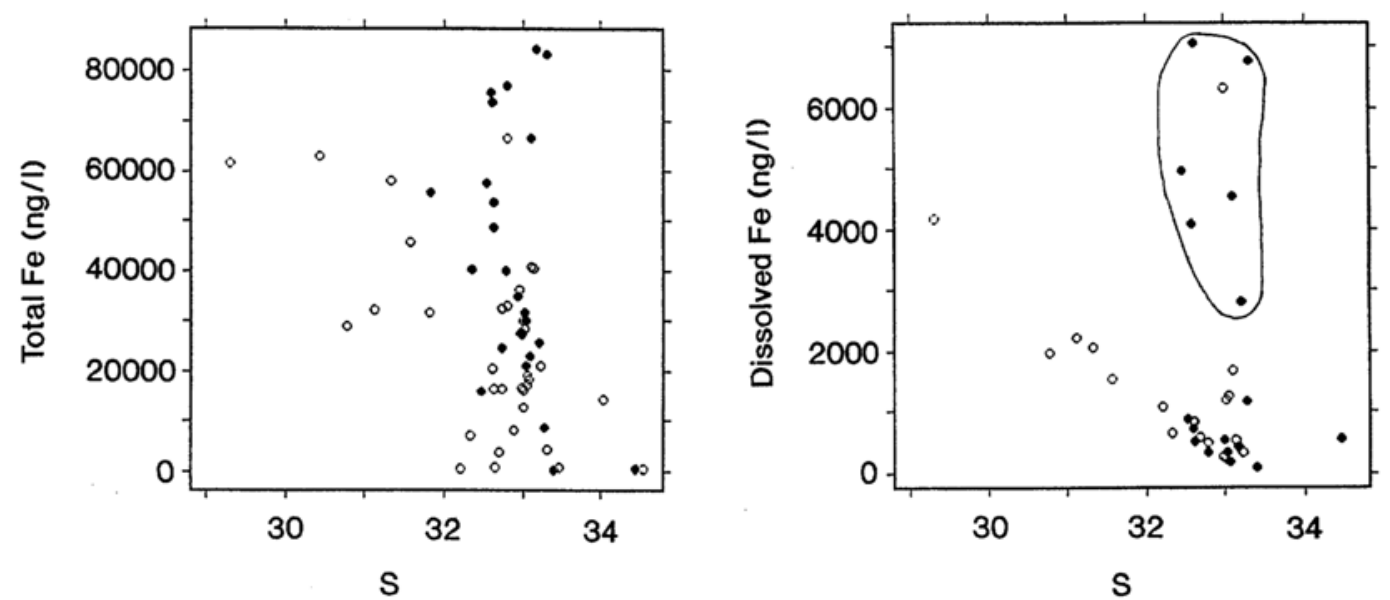

Fig. 2. Total and dissolved Fe concentrations vs. salinity. (०) surface water; (•) subsurface or bottom water. Points categorized with a line are for the inner part of Hiroshima Bay in June '83, see text.
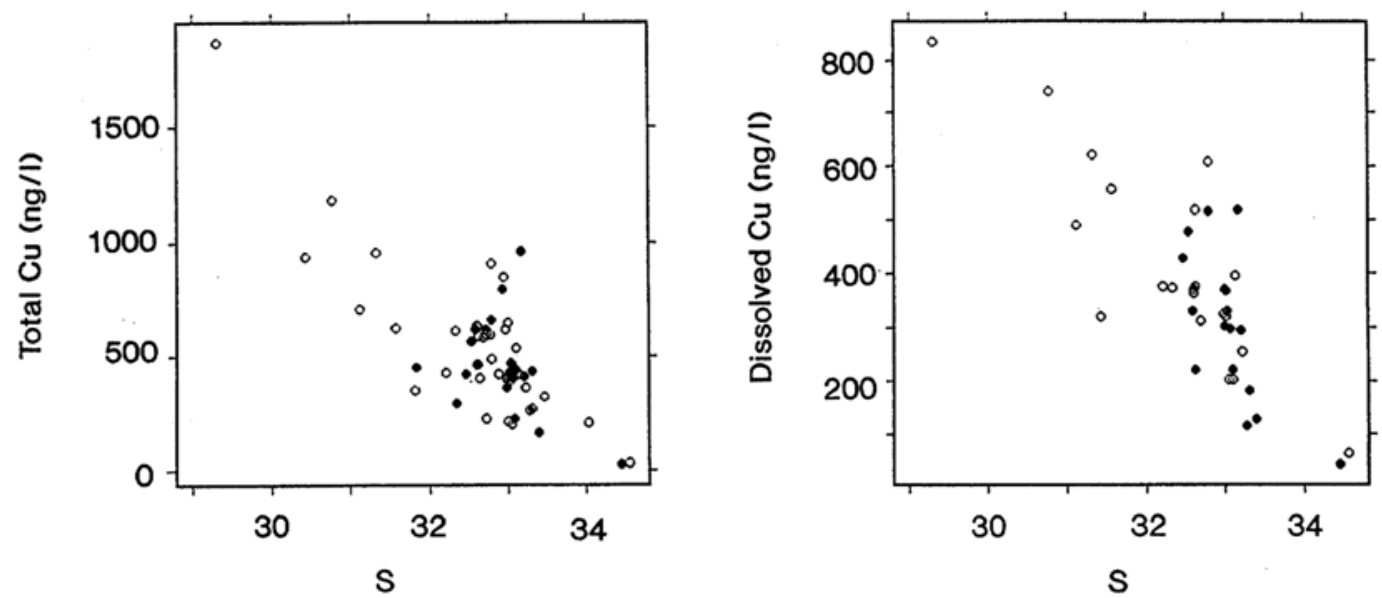

Fig. 3. Total and dissolved Cu concentrations vs. salinity. (О) surface water; (•) subsurface or bottom water.

\section{methods}

To separate the particles, centrifugal and filtration methods were employed on a cruise-bycruise basis. The analytical results showed some differences. By comparing these two methods, it may be possible to obtain good information on the characteristics of the heavy metal particulates. Generally, particles are removed by specific gravity with a centrifuge and by particulate size with filtration. The centrifugal method was employed only for the cruise near the vessel base, where we could use a centrifuge. Then, another cruise confirmed the difference be- tween the two method in Nov. 1985. The results of the comparison for $\mathrm{Fe}$ and $\mathrm{Pb}$ are given in Fig. 5, as an examle. ST-1, 2, 3 and 4 in the figure are near stations A-1, $-4,-6$ and -8 in the June 1983 cruise, respectively (cf. Fig. 1). The filtration method removed more particles than the centrifugal method for Fe. In contrast, in the case of $\mathrm{Pb}$, the centrifugal method removed more particles than the filtration method, except for ST-1. The reason for this exception is not clear yet, although the centrifugal separation of the samples from ST- 1 was delayed by about 20 hrs. These results suggest that particulate $\mathrm{Fe}$ may 

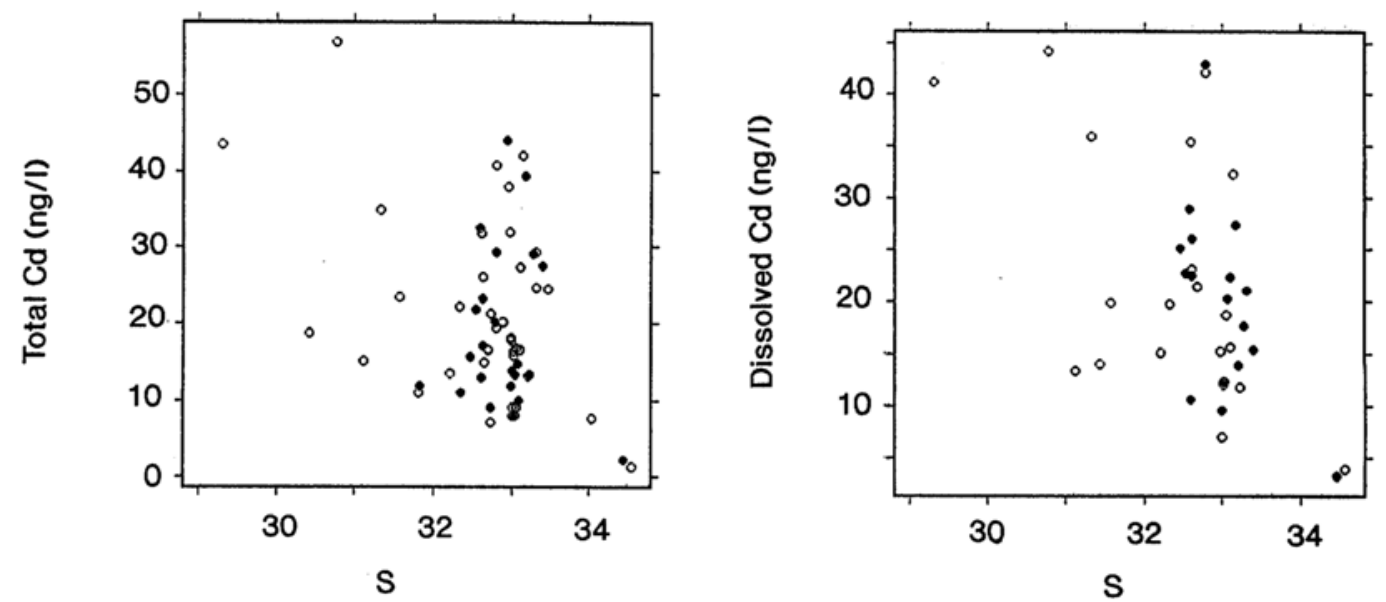

Fig. 4. Total and dissolved Cd concentrations vs. salinity. (О) surface water; (৫) subsurface or bottom water.

consist of relatively large-size and a light particles, such as gelatinous hydrated oxide or particulate organic matter, while $\mathrm{Pb}$ may contain small but heavy particles. $\mathrm{Mn}, \mathrm{Cu}, \mathrm{Zn}$ and $\mathrm{Co}$ had the same tendency as Fe.

Transport of heavy metals from rivers to the ocean through the Seto Inland Sea

The ten heavy metals analyzed were divided into three groups in accordance with the ratio of dissolved to total concentrations for the Seto Inland Sea. The transport of heavy metals from rivers to the ocean through the Inland Sea is schematically shown in Fig. 6. In this figure, downward arrows show the removal from seawater as particles, and upward arrows show the return into seawater as the dissolved form.

A large part of $\mathrm{Fe}, \mathrm{Mn}$ and $\mathrm{Pb}$ carried from land is removed rapidly at the river mouth as particles, while a small part is transported to the ocean through the offshore area of the Inland Sea. Feely et al. (1986) pointed out that particulate $\mathrm{Fe}, \mathrm{Mn}$ and $\mathrm{Pb}$ were rapidly scavenged as hydrated oxide. Kasemsupaya et al. (1989) reported that ${ }^{210} \mathrm{~Pb}$ was largely removed offshore in the early stage of mixing between the Kuroshio and the coastal waters. In these processes, a small amount returns again from the sediment. $\mathrm{Cu}, \mathrm{Zn}$ and $\mathrm{Co}$ are gradually removed as particulates. The ratios of their particulate form are reduced during the transport to the ocean by mixing with oceanic water. $\mathrm{Cu}$ may precipitate with humic acids and iron hydrated oxides as reported by Sholkovitz and Copland (1981). Cd, $\mathrm{Ni}$, Mo and $\mathrm{V}$ are mostly in the dissolved form and hardly removed as particles at the river mouth. They are transported to the ocean mostly in the dissolved form by mixing with oceanic water. Mo concentrations in oceanic water are higher than those in estuarine water, so that Mo is transported from the ocean to the Inland Sea by mixing with oceanic water.

Sometimes, $\mathrm{Pb}$ shows a character intermadiate between the first and the second groups, while $\mathrm{Ni}$ between the second and third groups.

\section{Flux of heavy metals from the Seto Inland Sea to} the open ocean

Estimates of the flux of heavy metals from the Seto Inland Sea to the open ocean are based on two assumptions as follows.

1. Particulate heavy metals are removed to sediment in the Inland Sea.

2. Only the dissolved form of heavy metals is transported out to the open ocean by mixing with oceanic water from the Inland Sea.

These assumptions have some difficulties. One is the neglect of the re-dissolution process. As shown in Fig. 2, a high concentration of dissolved $\mathrm{Fe}$ is sometimes observed, particularly at the 
lyo Nada Hiroshima Bay
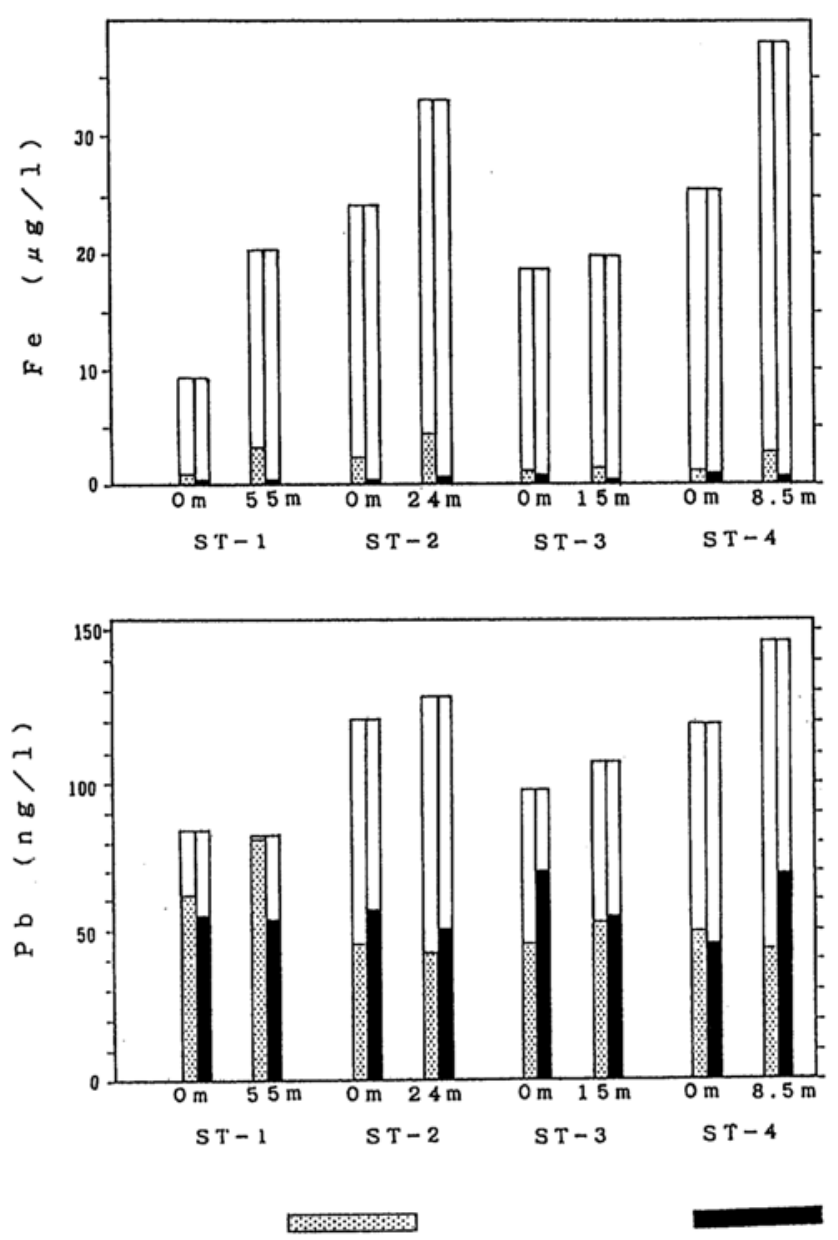

Supernatant centrifugallzed

Filtrate

Fig. 5. Comparison between the centrifugal method and the filtration method. Concentrations of $\mathrm{Fe}$ and $\mathrm{Pb}$ for the Nov. 1985 cruise.

red tide period, but it is accompanied by a high concentration of organic substances. This may be a temporal and local phenomenon observed only at the innermost part of the bay. The second assumption follows from the fact that the ratios of the particulate form for $\mathrm{Cu}$ in the Inland Sea are almost constant and decrease in the open ocean.

The fluxes of heavy metals are calculated by the equation:

$$
\text { Flux } \fallingdotseq \mathrm{V}_{\mathrm{o}}\left(\mathrm{C}_{\mathrm{i}}-\mathrm{C}_{\mathrm{o}}\right) / \tau_{\mathrm{w}}
$$

where $\mathrm{V}_{\mathrm{o}}$ is the seawater volume in the Inland Sea $\left(530 \mathrm{~km}^{3}\right)$, and $\tau_{\mathrm{W}}$ is residence time of seawater of the Inland Sea (1.2y, Takeoka, 1984; Fujiwara, 1985). $C_{i}$ is the average concentration of the dissolved heavy metal in the Inland Sea, and $\mathrm{C}_{\mathrm{o}}$ is the concentration of the dissoved heavy metal in the surface layer of the open ocean. The

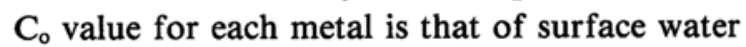
collected at $29^{\circ} 05^{\prime} \mathrm{N}, 142^{\circ} 51^{\prime} \mathrm{E}$, by the same authors.

The parameters and results of the calculation are given in Table 4. High concentrations of $\mathrm{Fe}$, 

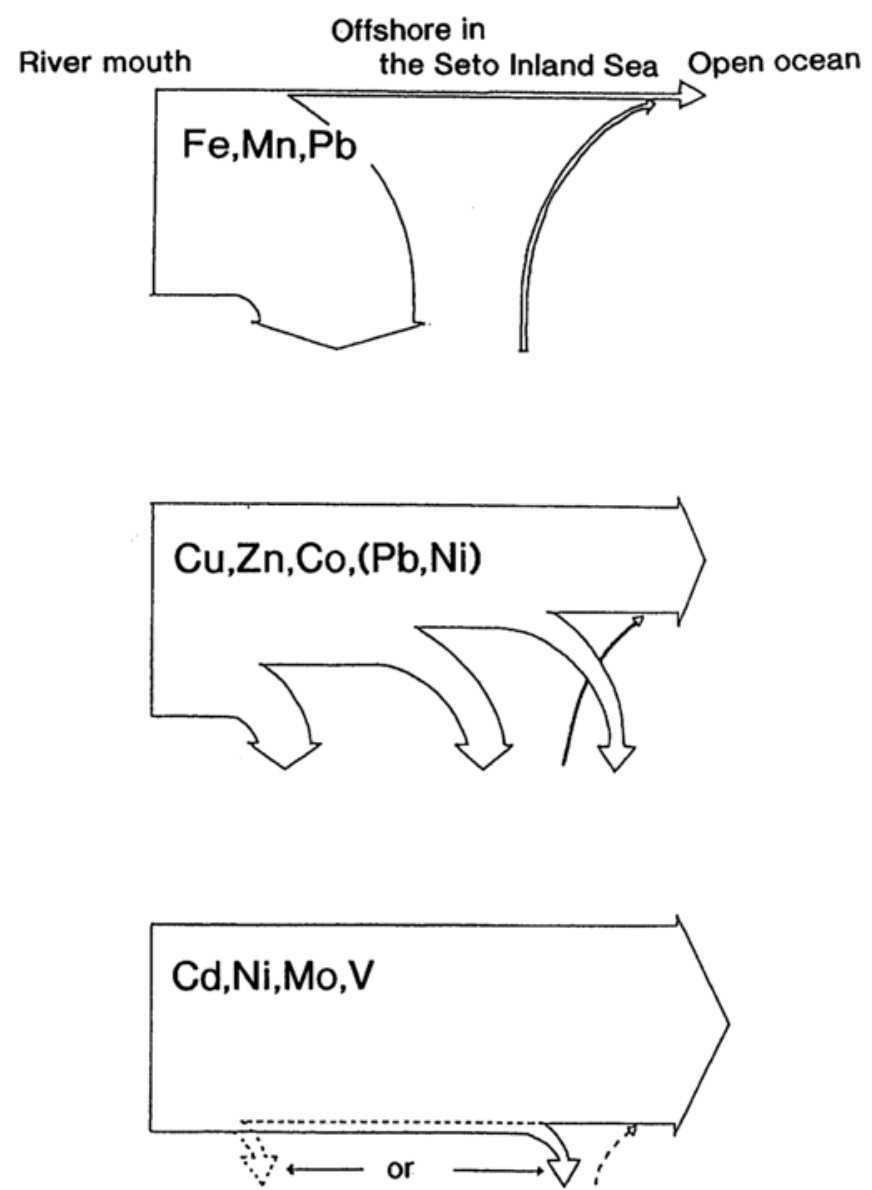

Fig. 6. The schematic diagram for transport of heavy metals from rivers to the ocean through the Seto Inland Sea.

Table 4. The flux of heavy metals from the Seto Inland Sea to the ocean

\begin{tabular}{lcccccccccc}
\hline & $\mathrm{Fe}$ & $\mathrm{Mn}$ & $\mathrm{Pb}$ & $\mathrm{Cu}$ & $\mathrm{Zn}$ & $\mathrm{Co}$ & $\mathrm{Cd}$ & $\mathrm{Ni}$ & $\mathrm{Mo}$ & $\mathrm{V}$ \\
\hline $\begin{array}{l}\text { Flux } \\
\text { (ton/year) }\end{array}$ & 270 & 400 & 19 & $\begin{array}{c}160 \\
(240)\end{array}$ & $\begin{array}{c}300 \\
(750)\end{array}$ & 4 & 13 & 97 & -440 & 180 \\
$\mathrm{C}_{\mathrm{i}}$ & 0.7 & 1 & 0.05 & 0.4 & 0.7 & 0.02 & 0.03 & 0.35 & 10 & 2 \\
$(\mu \mathrm{g} / \mathrm{l})$ & & & & & & & & & & \\
$\begin{array}{l}\mathrm{C}_{\mathrm{o}} \\
(\mu \mathrm{g} / \mathrm{l})\end{array}$ & 0.1 & 0.09 & 0.007 & 0.04 & 0.02 & 0.01 & 0 & 0.13 & 11 & 1.6 \\
\hline
\end{tabular}

The values in parenthesis are reported by Hoshika et al. (1988).

$\mathrm{Mn}$ and $\mathrm{Pb}$ are supplied to the Inland Sea through rivers. However, a large part of these metals is removed in the Inland Sea and their fluxes are small. The flux of Mo is negative. This shows that Mo is supplied from the ocean to the
Inland Sea. Hoshika et al. (1988) reported the flux of $\mathrm{Cu}$ and $\mathrm{Zn}$ from the Inland Sea to the ocean. These values, cited in parenthesis in the table, are higher than those calculated in this study. They estimated these values by using the 
sedimentation rates and heavy metal contents of the core sediments, and also different values for $\tau_{\mathrm{W}}$ and $\mathrm{C}_{\mathrm{o}}$. The difference suggests, if their estimation is shown to be better than the present study, that some of the particulate $\mathrm{Cu}$ and $\mathrm{Zn}$ may be transported out to the ocean contrary to our assumption that only dissolved forms are transported.

Acknowledgments-The authors are sincerely grateful to Prof. Tomoo Hayashi and the late Prof. Takuro Endo, Faculty of Applied Biological Science, Hiroshima University, for their useful suggestions and help in the sampling. Thanks are also extended to the captain and crew of the R/V Toyoshio Maru for their kind help in the sampling. The authors wish to thank Prof. Yuroku Yamamoto, Prof. Takahiro Kumamaru and Dr. Manabu Yamamoto for their help and advice in the using of the atomic absorption spectrophotometer. This work has been supported by the Ministry of Education, Science and Culture, Japan through a Grant in-Aid Nos. 58030051, 58102012, 60035041 and 61035046.

\section{REFERENCES}

Ackroyd, D. R., A. J. Bale, R. J. M. Howland, S. Knox, G. E. Millward and A. W. Morris, (1986) Distributions and behavior of dissolved $\mathrm{Cu}, \mathrm{Zn}$ and $\mathrm{Mn}$ in the Tamar Estuary. Est. Coast. and Shelf Sci. 28, 327-338.

Akagi, T., H. Haraguchi and H. Tsubota, (1988) A study on mineral composition of suspended particles in coastal estuarine water using X-ray diffractiometry. Chem. Lett. 1988, 331-334.

Akagi, T., T. Kodama, H. Haraguchi, K. Fuwa and H. Tsubota, (1986) Distribution of heavy metals in seawater around the Shikoku Island. Geochem. J. 20, 127-135.

Batley, G. E. and Garoner, (1978) A study of copper, lead and cadmium speciation in some estuarine and coastal marine waters. Est. Coast. Mar. Sci. 7, 5970.

Boyle, E. A., J. M. Edmond and E. R. Sholkovitz, (1977) The mechanism of iron removal in estuaries. Geochim. Cosmochim. Acta 41, 1313-1324.

Danielsson, L. G., B. Magnusson, S. Westerlund and K. Zhang, (1983) Trace metals in the Göta River Estuary. Est. Coast. Shelf Sci. 17, 73-85.

Feely, R. A., G. J. Massoth, E.T. Baker, J. F. Gendron, A. J. Palson and E. A. Crecelius, (1986)
Seasonal and vertical variations in the elemental composition of suspended and settling particulate matter in Puget Sound, Washington. Est. Coast. Shelf Sci. 22, 215-239.

Fujiwara, T. (1985) Flux and Balance of Mass in the Seto Inland Sea. Ph. D. thesis, Tokyo University.

Gibbs, R. J., (1986) Segregation of metals by coagulation in estuaries. Mar. Chem. 18, 149-159.

Hardy, J. T., C. W. Apts, E. A. Crecelios and N. S. Bloom, (1985) Sea-surface microlayer metals enrichments in Urban and Rural Bay. Est. Coast. Shelf Sci. 20, 299-312.

Hart, B. T. and S. H. R. Davies, (1981) Trace metal speciation in the freshwater and estuarine regions of the Yarra River, Victoria. Est. Coast. Shelf Sci. 12, 353-371.

Hayami, S. and S. Unoki, (1970) Water exchange and material dispersion in the Seto Inland Sea. Proceedings of the 17th Conference on Coastal Engineering. Japan Society of Civil Engineers. 358393.

Hoshika, A., T. Shiozawa and Y. Kitano, (1988) Mass balance of heavy metals in the Seto Inland Sea, Japan. Mar. Chem. 24, 327-335.

Kasemsupaya, V., M. Yashima, H. Tsubota and Y. Nozaki, (1989) Comparative behavior of ${ }^{210} \mathrm{~Pb}$ and $\mathrm{Ra}$ isotopes in the waters of Tokyo Bay and Osaka Bay mixing zones. Geochem. J. 23, 129-138.

Li, ' Y. H., L. Burkhardt and H. Teraoka, (1984) Desorption and coagulation of trace elements during estuarine mixing. Geochim. Cosmochim. Acta 48, 1879-1884.

Mart, L. and H. W. Nurnberg, (1986) Cd, Pb, Cu, Ni and Co distribution in the German Bight. Mar. Chem. 18, 197-213.

Sholkovitz, E. R. (1978) The flocculation of dissolved $\mathrm{Fe}, \mathrm{Mn}, \mathrm{Al}, \mathrm{Cu}, \mathrm{Ni}, \mathrm{Co}$ and $\mathrm{Cd}$ during estuarine mixing. Earth Planet. Sci. Lett. 41, 77-86.

Sholkovltz, E. R. and Copland D., (1981) The coagulation, solubility and adsorption properties of $\mathrm{Fe}, \mathrm{Mn}, \mathrm{Cu}, \mathrm{Ni}, \mathrm{Cd}, \mathrm{Co}$ and humic acids in a river water. Geochim. Cosmochim. Acta 45, 181-187.

Takeoka, H., (1984) Exchange and transport time scales in the Seto Inland Sea. Continental Shelf Res. 3, 327-341.

Tsubota, H. (1985) The distribution and behavior of heavy metals in the ocean. Ocean Characteristics and their changes chapter 4, 225-236, ed. K. Kajiura, Koseisha Koseikaku, Tokyo (in Japanese).

Windom, H., G. Wallace, R. Smith, N. Dudek, M. Maeda, R. Dulmage and F. Stori, (1983) Behavior of copper in southeastern United States estuaries. Mar. Chem. 12, 183-193. 